\title{
Connotation, Restriction Factors and Promotion Strategies of Practical Innovation Ability of Young Teachers in Applied Universities
}

\author{
Wang Ting \\ Applied Technology College \\ Dalian Ocean University \\ Dalian, China \\ wangwt_1978@163.com
}

\begin{abstract}
Practice-type innovative young teachers are the key force to cultivate innovative talents and build an innovative-oriented country. But the deficiency of young teachers' practical innovation ability has become an important problem in the training of innovative talents in applied universities. Therefore, this paper tries to define the connotation of applied young teachers practice innovation ability, analyze influence factors by the analytic hierarchy process, and put forward the Strategies to develop practical innovation ability of young teachers in applied universities.
\end{abstract}

\section{Keywords-Applied Universities; Teachers; Innovation Ability}

\section{INTRODUCTION}

Applied universities are developed with the development of the social economy to a certain stage. Applied universities are based on providing services for local place and assuming the mission of cultivating talents for the regional economic development and the revitalization of the industry. They are the incubator of innovation spirit and the innovative talents cultivation. The practice-type innovative young teachers are the most active and new force in the teaching team of applied universities with the pioneering spirit, continuous development and innovation. They are the key force to promote the construction of innovative country, revitalize the country through talents, implement innovative-driven development strategies, and cultivate innovative talents. Therefore, to strengthen and attach importance to the practice innovation ability of young teachers, build a practice-type innovative teaching team, and improve the core competitiveness of the applied universities plays an important role in the training quality of talents required for national economy construction.

The shortage of practical innovation ability of young teachers has become an important problem for innovative talents training in applied universities. The practical innovation ability of young teachers greatly affects the education and teaching level of Applied Universities, the training of applied talents, the transformation and upgrading of national industrial structure, the innovation of science and technology, etc.

\section{CONNOTATION OF PRACTICAL INNOVATION ABILITY}

From the psychological point of view, ability is seen as a psychological feature [1] that can affect the purpose of behaviors by means of factors such as emotion, attitude, language, action, etc. James D. Klein [2]. , through the definition of ability by IBSTPI (International Board of Standards for Training, Performance and Instruction), pointed out that ability is not only a personal internal characteristic, but also a kind of explicit behavior manifested by attitude. Explicit behavior can be measured by certain standard that is acceptable to all, so that the ability is "a complex of knowledge, skills and attitudes that enable individuals to effectively complete activities for specific occupations or to achieve universal acceptance criteria" [3].

People's cognition of the practical innovation ability of young teachers is closely related to the research of teacher's teaching ability, while the research of teacher's teaching ability lies in clarifying the connotation of teaching ability for quite a long time. The research of teacher's teaching ability has aroused extensive concern since the 1950s. Some domestic scholars[4] [5] [6] think that teacher's teaching ability is a psychological characteristic composed of the general abilities and special abilities such as observation, memory, imagination, attention, thinking ability and so on. It is the teacher's ability of cognition, operation and monitoring manifested in the teaching activities to achieve the goal of teaching. Dineke [7] further externalizes and makes qualitative the teacher's teaching ability, and embeds the teacher's basic ability into the teaching situation or teaching activities. He thinks that teaching ability is the required comprehensive psychological characteristic, intelligence characteristic or behavior characteristic of the teacher as the individual to engage in teaching activities, and is the knowledge, skills and attitudes needed to support the effective teaching performance in various teaching environments.

Practical innovation ability is conceived in teacher's teaching ability and is regarded as a constituent factor contained in teacher's teaching ability, which acts as a practical thinking and creative thinking, not a separate practical operation skill. Teachers' teaching ability is regarded 
as a combination of general ability and special ability based on cognitive ability, which contains three most critical and most important abilities including the analytical thinking, creative thinking and practical thinking, directly connects the characteristics of teachers' basic ability and teaching aim, teaching efficiency and effects, and points out that the basis of the teaching ability of teachers in universities is the four kinds of intelligence activity characteristics of analytical thinking, critical thinking, creative thinking and practical thinking. On this basis, the teaching ability can be divided into three levels, i.e. the intelligence basis of teaching ability (analytical thinking ability, creative thinking ability, practical thinking ability), general teaching ability (teaching monitoring ability, teaching cognitive ability, teaching operation ability), and specific subject teaching ability [8]. Some scholars point out clearly that teachers' teaching ability includes the connotation and elements of practical innovation ability[9] [10] [11], such as curriculum development and construction ability, practical teaching ability, scientific research ability, innovation ability, transformation ability of scientific research achievements, social service ability and so on. However, the teaching ability of university teachers is necessary for their successful completion of teaching activities and directly affects the individual psychological characteristics of teaching activity efficiency. It is a kind of professional quality formed by teachers in certain teaching situations and through teaching activities to transform personal intelligence and teaching knowledge and skills. It depends on certain intelligence and is a kind of special ability (professional ability) [12] [13] based on cognitive ability until there is someone defining the practical innovation ability, pointing out that practical innovation ability of applied university teachers is the third dimension to distinguish the practical operation ability and practice teaching ability[14].

Practical innovation ability reflects the status and function of teachers in applied universities, which is the development of the basic teaching ability of their young teachers. Practical innovation ability can be regarded as the advanced stage of the development of basic practical ability and comprehensive practical ability. It is the ability for the young teachers in applied undergraduate universities to consciously apply the cultural basic knowledge, professional knowledge and basic skills to form creative thinking and creatively solve practical problems through continuous practice, exploration, and research, in a specific social practice environment. The innovation consciousness, innovation spirit, innovative thinking and innovation ability can be regarded as its characteristics. Practical innovation ability is more pragmatic, practical and operable, and it is the key link to improve the skill and practicality of applied education. The position responsibility and career planning of the applied university teachers require the young teachers to have certain practical creative ability, and examine the practical innovation ability of the applied university teachers from the perspective of teachers' profession, disciplinary development and social role.

The young teachers in applied universities undertake the basic tasks such as practical teaching, scientific research, social services and inheritance of skills, and ensure the smooth development of the education and teaching activities in the disciplinary and professional field in the cultivation process of practical innovation ability. The shaping of the young teachers' innovative conducts, the cultivation of innovative thinking and the improvement of innovative quality greatly affect the cultivation of practical innovative talents in applied universities, and marks the improvement of teacher's individual professional technical ability. In the process of guiding the students' practical teaching and innovative practice activities, the young teachers in applied universities apply innovative ideas, innovative technologies, tools and methods to actively carry out the renewal and development of the education and teaching through the flexible teaching mode so as to cultivate the students' innovation and entrepreneurship attainments.

\section{FACTORS RESTRICTING THE PRACTICAL INNOVATION} ABILITY

The implementation of innovation-driven development strategy and the construction of an innovation country need to cultivate practical innovative talents. Universities are the most dynamic and innovative places, and undertake the task of cultivating practical innovative talents. This needs to create an atmosphere of innovation strategy, innovation theory, innovation spirit, innovative thinking, innovation ability, and other macroeconomic environments from the aspects of society, culture, and legal system, and form a cultural atmosphere which is open and inclusive, advocates freedom, promotes innovation, and is bold in making practice in the applied universities.

At present, the applied universities fail to have sufficient recognition of the strategy and importance of the development of young teachers' practical innovation ability. The number of "double-qualified teachers" and "skilled teachers" is not sufficient. There exists prominent phenomenon of serious shortage of practical innovation ability of young teachers. Due to the special historical and cultural atmosphere, the golden mean of Confucianism and the inaction thoughts of Taoism influence the sub-consciousness and thinking logic of the teachers in applied universities, which make them lack of innovation motivation, innovation spirit and innovation consciousness. This seriously affects the quality and scale of innovative talents cultivation in applied universities. Although young teachers have strong demands to enhance their practical innovation ability, the performance appraisal system, job title evaluation system, job promotion policy and personnel management policy of applied universities have not been inclined to the practical and innovative young teachers, which have impeded the young teachers' subjective initiative to improve their innovation ability to some extent. In the aspect of the career development of young teachers, there is a lack of practical innovative learning platform to replace their innovative thinking, transform the innovation concept, improve the innovation quality, stimulate the innovation spirit and cultivate the practical innovation ability, and there lacks the corresponding transformation period of practical innovation activities to implement the innovation results. All these have seriously restricted the development of the practical innovation ability of young teachers in applied universities. 
Due to the lack of educational resources possessed by the applied universities, teachers' lack of systematic education in their pre-service education that sets the cultivation of innovative knowledge as the concept and purpose, and the deficiency of expenditures used in the experiments, scientific research, investigation and other aspects of practical innovation, the young teachers have serious utilitarian mentality under the meager wages and lack special training on the quality of innovative consciousness, innovative spirit, innovative thinking, innovation ability, etc.

Based on the above analysis, the cultivation and development of the practical innovation ability of young teachers in applied universities are influenced by the innovation environment and the teacher's own factors. The innovation environment includes macro-environment, meso-environment and micro-environment. The macro-environment includes the political, economic, social, legal system, cultural environment, professional environment and social environment of the country. To be specific, it refers to the national policies and systems, disciplinary development plan, personnel training plan and social factors. The meso-environment includes the development of the education industry in which the applied universities are located, the setting of the discipline and specialty, and the construction environment, as well as the self-orientation and development strategy of the applied universities and the setting of the objective of talents training. Teachers' own factors refer to the expectation of the young teachers in applied universities on career development, their orientation of self-development, the requirement on self-quality improvement, etc.

Specifically, the basic factors that restrict the practical innovation ability of young teachers in applied universities are as follows:

\section{A. Institutional environment for the protection of innovation rights}

The legal system provides a solid system guarantee for the formation and development of the practical innovation ability, and creates an institutional environment conducive to the cultivation of the practical innovation ability of young teachers. The revision and perfection of the legal system, such as the Property Law, the Intellectual Property Law and the Patent Law, as well as the implementation of the laws and regulations for respecting the achievements of knowledge innovation, are favorable for protecting the legitimate rights and interests of the innovators; the formulation of the national innovation policy, the special plan for innovative talents training and the development of the fund projects, affect the macro-institutional environment that generates and brings into force the practical innovation ability of the young teachers in applied universities, and is conducive to forming the patterns of young teachers in technical universities to be bold in innovation and good at innovation.

\section{B. Professional career and discipline development planning.}

The national science and technology industrial development plan points out the training direction of the country's innovative talents, guides the training categories of the practical innovative talents, promotes the young teachers in applied universities to cultivate and strengthen the practical innovation ability, and influences the establishment, decrease and increase of the relevant disciplines and majors, so as to meet the needs of the society for different innovation abilities.

\section{Objective Orientation and Development Strategy of Universities}

Practical innovative young teachers are an important force for the applied universities to realize the development strategy, educational philosophy and disciplinary positioning. The factors such as the purpose, the development orientation and the talent training of applied universities restrict the development of applied universities, and determine the career orientation and career development goals of the practical innovative young teachers.

\section{Teacher System}

The qualification certification system, registration system, job title evaluation system and the employment system for the young teachers in applied universities can confirm the qualifications of the young teachers in applied universities, and effectively define the basic practical innovation ability of the young teachers in applied universities. The quantity and quality of young teachers with innovation ability basically determines the strength and weakness of the practical innovation ability of applied universities and whether young teachers are competent to the practical teaching tasks.

\section{E. Teacher growth mechanism}

The talents training mechanism, practical innovation ability training mechanism, practical teaching quality evaluation mechanism, and the efficiency incentive mechanism and so on influence the growth of the practical innovative young teachers. Create a good environment for the practical innovative teachers to succeed, and tend to focus on the practical innovative young teachers in the aspects of training and advanced studies, scientific research projects declaration, achievement identification, job title evaluation, teaching quality evaluation and so on, so as to effectively stimulate the growth and success of young teachers and promote the development of practical innovation ability.

\section{$F$. Teachers' basic quality and self-development orientation}

The young teachers of applied universities are the only carriers of their practical innovation ability. The practical innovation ability of young teachers in applied universities is influenced by its individual character, knowledge system, professional attainments, professional ethics and practical innovation experience. The personal needs, professional attitudes and professional ethics of the young teachers in applied universities provide the original driving force for their practical innovation ability, and determine their motivation and expectation of undertaking the practical innovation teaching; the innovative concepts, knowledge structure and professional quality of the young teachers in applied universities determine the development level and promotion path of their practical innovation ability. 


\section{STRATEGIES FOR IMPROVING PRACTICAL INNOVATION ABILITY}

Adapting to the development and social progress of the times, creating a macro-environment for implementing the innovation-driven development strategy and building an innovative country, strengthening the construction of practical and innovative teachers' team, establishing and perfecting the system and mechanism for improving the practical ability of young teachers, are the key to cultivate the practical and innovative talents.

The applied universities are the platform for the cultivation of the young teachers' practical innovation ability. The applied universities need to carry out comprehensive teaching reform, set up the innovation concepts, innovation consciousness and innovation spirit, establish the teaching team for the practical innovation of the practical and innovative young teachers, establish an incentive mechanism to stimulate the teacher's practical innovation behaviors, and explore the cultivation modes of the practical innovation ability of the young teachers in applied universities.

As the young teachers of applied universities, they should combine the practical innovation ability with the national development, social needs, the university's requirements and the individual's demands, and build themselves into practical innovative talents.

Specially speaking, the improvement of the practical innovation ability of the young teachers in applied universities can take a series of policy measures and suggestions from the macro, meso and micro levels, and in particular, can be carried out from the following aspects:

(1) Develop and implement the medium and long-term practical innovative talent development strategy, and promote the cultivation of the practical innovation ability the young teachers in applied universities. Formulate the development plan of the young teachers in applied universities from the macroscopic level, encourage the applied universities, industry departments (associations) to formulate practical innovative talent evaluation standards, layout the practical innovative talent strategy, set up a talent training fund, support the practical innovation and development projects, and set the students as the main body, the application-oriented young teachers as the leading, to innovate the educational modes and promote the cultivation of the "double-qualified" outstanding young teachers that have "professional practice + innovative practice". The young teachers in applied universities should establish corresponding, scientific and reasonable practical innovative talent qualification audit system and practical innovation ability identification mechanism based on the planning requirements of strategy on practical innovative young teachers at the national level and according to the introduction plan of practical innovative talents, introduce the talents according to the demands, introduce the true talents, and adopt various kinds of introducing modes, such as core innovative talents driving the introduction to introduce practical innovative talents of different disciplines, different specialties and different levels.

(2) Develop the practical innovation skill standards, and encourage the outstanding young teachers to improve the practical innovation ability. The practical and innovative skills standards committee composed of government supervision, industry undertaking and university-enterprise selection implements the national standard of teaching quality, defines the connotation, ability standard and quantitative index of practical innovation skills, implements the industry qualification access system and the qualification system of the young teachers in the applied universities, regulates the basic requirements for the cultivation of the young teachers in universities, and select outstanding practical innovative talents through the assessment, evaluation and cultivation of the young teachers in the applied universities.

(3) Innovate the practice mechanism and give play to the function of the practical innovation exchange mechanism. The universities should strengthen the connection with society, make use of all available resources, encourage the young teachers to enter the grass-roots level, factory workshops, technical departments or function departments, truly understand the truth of society, seek effective ways of realizing the situation and theoretical innovation, knowledge innovation and technological innovation, and enhance the practical innovation ability. It can also make the university teachers participate in the activities such as technological innovation or subject research in the enterprises, so as to improve the social adaptability of young teachers' innovative ability in universities. Actively carry out internal and external cooperation and exchanges, adopt the methods of cooperation, exchange, exchange, etc., select a certain number of backbone teachers as visiting scholars and exchange scholars to receive advanced education at home and abroad and carry out academic exchanges and scientific research cooperation, learn from other universities' achievements in the aspects of management, mechanism, system, culture construction and so on, jointly discuss the reform of the teaching modes and teaching means in training the practical innovative talents, so as to cultivate the "double-qualified" master-level application-oriented practical innovation young teachers.

(4) Reform the university teacher system, enrich the practical innovation young teachers' team, and optimize the practical innovation teacher group. Reform the acquisition modes of university teachers' qualification certificate, and encourage the experts, inventors and professional technicians with rich practical skills and strong innovative consciousness in the enterprise and industry fields to cross-border enter into the teaching field of universities. Guide the industry enterprises to further participate in the standard formulation and teaching evaluation of professional teaching, substituted post practice, post qualification certification and so on. Be strict in teacher's professional admittance, implement the method of combining the teacher's job title review with the post employment, lower the teacher's professional title appraisal right, set up the university teacher's professional title evaluation system with the characteristics of applied education, and perfect the teacher's professional title system. Through the diversified and professionalized teaching evaluation mechanism of the university teachers, assess their professional qualifications and practical teaching ability of vocational education, actively promote the "double certificate" 
system, co-ordinate the relevant courses examination and professional skills appraisal, and issue teacher qualification certificate to qualified applicants according to professional standards and job requirements, so as to enrich the practical innovative teaching team of applied universities. On the basis of the development of new situation, the applied universities should innovate the training modes and focus on cultivating the leaders in innovative education discipline, constructing and supporting a group of innovative talents training models of "innovative team leader + innovation team" with reasonable structure, complementary advantages, unity and cooperation, cohesive force and combat effectiveness, guided by the talent structure and level optimization of teachers' team.

(5) Promote the comprehensive reform of the applied universities, and improve the practical innovation environment of young teachers. The applied universities should raise social funds and attract enterprises according to the factors such as disciplinary development, enrollment scale, teacher structure and specialty construction, increase the investment in the hardware construction of teaching facilities and software of practical innovative teaching, and tend to focus on the practical innovative young teachers in the aspect of teacher qualification registration, professional title appraisal, training and advanced studies, scientific research project declaration, achievements appraisal, and teaching quality evaluation, so as to create a good environment for the practical innovative teachers to succeed, effectively stimulate the growth of young teachers, and promote the development of practical innovation ability. The establishment of the incentive system and the mechanism should be scientific, reasonable and fair. Formulate an evaluation system, personnel distribution system and education, teaching management system and other management systems conducive to the teachers' professional development, the full play of the innovation potential, the improvement of teachers' innovation ability, etc., Create an environment conducive to the cultivation of practical innovative talents. Further promote the reform of the assessment and evaluation system of practical innovative young teachers in applied universities, set up a whole set of assessment and evaluation system which embodies the core of innovation, and overcome the tendency of education-only, professional title-only, paper-only, etc. Take the practical innovation ability as the most important index to assess and evaluate the performance of the young teachers in applied universities, and as the main basis of the teaching staff assessment, promotion, job title and job employment, remuneration distribution and so on. Implement the principle of better payment for better work, conscientiously execute the performance wage system, pay attention to evaluating the talents according to the ability, performance and contribution, and improve the salary distribution system of the innovative young teachers with the characteristics of applied universities.

(6) Taking the production and research as the link, strengthen the platform and the base construction for the experiment, training, and practice, establish and perfect the teaching and learning integration, the university-enterprise cooperation and the production and research as one, so as to construct a "double-qualified teachers" practical innovation team. Strengthen the normal input of curriculum construction and teaching reform, establish a cooperative education mechanism for the universities to cultivate talents with the enterprises, industry, scientific research institutions and communities, and strengthen the links in experiment, practical training and internship through integrated learning, scientific research and production, so as to achieve the systematization and the process in the aspects of objective training, program formulation, curriculum setup, content perfection, system optimization, practical innovation, practical training construction and teacher training, etc. In large and medium-sized enterprises, a pilot integration project of production and education is carried out to realize the co-cultivation of the integration of production and education, the integration of science and education, promote the co-construction of talents training bases, technical innovation bases, scientific and technological service bases in the industry and schools, and effectively improve the practical innovation skills, thus being beneficial to the construction of "double-qualified" young teachers team in applied universities.

(7) Promote the self-development orientation of application-oriented young teachers and encourage the young teachers to improve the practical innovation ability. Perfect the training and education system and management system of application-oriented practical innovation talents, and actively guide and inspire the young teachers in applied universities to make clear the goals and approaches of career development and set up the development plan of self-career, revolving around the national strategy of revitalizing the country through science and education and the applied universities' innovative talents training plan. Establish a practical innovation and career promotion platform for application-oriented young teachers, attract and encourage the teachers to participate actively in the training of practical innovation skills, and improve the practical innovation teaching skills and level. Combining personal needs, professional attitude, knowledge system, professional attainments, innovative quality and practical innovation experience, through participating in training and other ways, and setting the improvement of practical innovation ability as the opportunity, enhance the professional identity and sense of belonging of the young teachers in applied universities and constantly enhance the motivation and expectation of undertaking practicing innovative teaching.

\section{CONCLUSIONS}

Practical innovation ability is the ability for the young teachers in applied universities to solve practical problems creatively, which is restricted by the macro-system environment and subject planning, the orientation and development of the universities, the access of teachers and the development of growth. Therefore, it is necessary to adopt a series of policy measures to establish and perfect the practice innovation ability of the young teachers in applied universities. 


\section{ACKNOWLEDGMENT}

This research was financially supported by the General Research Project of the "13th Five-Year Plan" for National Agricultural Vocational Education, Exploration and Reflection on the Establishment and Improvement of the Practical Innovation Ability of Young Teachers (2016-135-Y-55); Scientific Research and Planning Project of the 13th Five-Year Plan for International Education in Liaoning Province (2016-2017), A Comparative Study on the Training Modes of Vocational Skills in Higher Vocational Education in Domestic and Foreign Countries (16LNGJ017); Scientific Research and Planning Project of Liaoning Vocational and Technical Education Institute (2017-2018), Research on the Teaching Reform of Higher Vocational Education under the Condition of Informatization (LZY17414).

\section{REFERENCES}

[1] [Ye Yiqian et al. General Psychology. [M]. Shanghai: East China Normal University Press, 2000: 586.

[2] Klein. Standard for Teacher's Competence. [M]. Shanghai: East China Normal University Press, 2007.

[3] Rita C. Richey, Dennis C. Fields, Marguerite Foxon. Instructional Design Competencies: The Standards. Third Edition. [M]. New York: Clearing house on Information and Technology, 2001:26, 33.

[4] Li Chunsheng. Encyclopedia of Primary School Teaching in China • Educational Volume [M]. Shenyang: Shenyang Publishing House, 1993.

[5] Gu Mingyuan, Education Dictionary. Shanghai Educational Publishing House. 1998 .

[6] Shen Jiliang and Wang Kairong. On the teacher's teaching ability [J]. Journal of Beijing Normal University, 2000 (1): 64-71.

[7] Dineke E. H. Tigelaar, Diana H. J. M. Dolmans, Dineke H. A. P. Wolfhagen \& Cees P.M. Van Der Vleuten. The development and validation of a framework for teaching competencies in higher education. Higher Education, 2004.

[8] Yue Xixi. On the basis of teaching ability of university teachers [J]. Occupation and Education, 2011 (6): 65-66.

[9] Li Juan and Fan Baoxing. The composition and cultivation of the higher vocational teachers' teaching ability. [J]. China Adult Education, 2009 (1): 89-90.

[10] Yuan Zhizhong and Yuan Daixiu. On the ways of improving the teaching ability of the teachers in universities. [J]. Journal of Higher Education, 2011(9): 65-67.

[11] Wu Yaqiu. Research on the evaluation index system of teachers' teaching ability in higher vocational colleges. [J]. Continue Education Research. 2012 (5): 67-69.

[12] Yu Chenghai and Yao Benxian. On the teaching ability structure of the teachers in universities and its optimization. [J]. Higher Agricultural Education, 2005, 12.53-56.

[13] Wang Xianping. A research on the development of teacher's teaching ability from the perspective of curriculum reform [D]. Doctorial Dissertation of East China Normal University, 2006.

[14] Liu Ping. The constitutional dimension of the practice ability of the teachers in the applied universities and the promotion strategy. [J]. China Education of Light Industry, 2016(4): 13-19. 